\title{
Understanding Natural Selection: Essential Concepts and Common Misconceptions
}

\author{
T. Ryan Gregory
}

Published online: 9 April 2009

(C) Springer Science + Business Media, LLC 2009

\begin{abstract}
Natural selection is one of the central mechanisms of evolutionary change and is the process responsible for the evolution of adaptive features. Without a working knowledge of natural selection, it is impossible to understand how or why living things have come to exhibit their diversity and complexity. An understanding of natural selection also is becoming increasingly relevant in practical contexts, including medicine, agriculture, and resource management. Unfortunately, studies indicate that natural selection is generally very poorly understood, even among many individuals with postsecondary biological education. This paper provides an overview of the basic process of natural selection, discusses the extent and possible causes of misunderstandings of the process, and presents a review of the most common misconceptions that must be corrected before a functional understanding of natural selection and adaptive evolution can be achieved.
\end{abstract}

Keywords Adaptation · Darwin · Evolution · Fitness · Mutation $\cdot$ Population $\cdot$ Variation

"There is probably no more original, more complex, and bolder concept in the history of ideas than Darwin's mechanistic explanation of adaptation."

Ernst Mayr (1982, p.481)

\section{Introduction}

Natural selection is a non-random difference in reproductive output among replicating entities, often due indirectly to differences in survival in a particular environment, leading to

T. R. Gregory $(\bowtie)$

Department of Integrative Biology, University of Guelph, Guelph, Ontario N1G 2W1, Canada

e-mail: rgregory@uoguelph.ca an increase in the proportion of beneficial, heritable characteristics within a population from one generation to the next. That this process can be encapsulated within a single (admittedly lengthy) sentence should not diminish the appreciation of its profundity and power. It is one of the core mechanisms of evolutionary change and is the main process responsible for the complexity and adaptive intricacy of the living world. According to philosopher Daniel Dennett (1995), this qualifies evolution by natural selection as "the single best idea anyone has ever had."

Natural selection results from the confluence of a small number of basic conditions of ecology and heredity. Often, the circumstances in which those conditions apply are of direct significance to human health and well-being, as in the evolution of antibiotic and pesticide resistance or in the impacts of intense predation by humans (e.g., Palumbi 2001; Jørgensen et al. 2007; Darimont et al. 2009). Understanding this process is therefore of considerable importance in both academic and pragmatic terms. Unfortunately, a growing list of studies indicates that natural selection is, in general, very poorly understood - not only by young students and members of the public but even among those who have had postsecondary instruction in biology.

As is true with many other issues, a lack of understanding of natural selection does not necessarily correlate with a lack of confidence about one's level of comprehension. This could be due in part to the perception, unfortunately reinforced by many biologists, that natural selection is so logically compelling that its implications become self-evident once the basic principles have been conveyed. Thus, many professional biologists may agree that "[evolution] shows how everything from frogs to fleas got here via a few easily grasped biological processes" (Coyne 2006; emphasis added). The unfortunate reality, as noted nearly 20 years ago by Bishop and Anderson (1990), is that "the concepts of evolution by natural selection are far more difficult for students to grasp than most biologists imagine." Despite 
common assumptions to the contrary by both students and instructors, it is evident that misconceptions about natural selection are the rule, whereas a working understanding is the rare exception.

The goal of this paper is to enhance (or, as the case may be, confirm) readers' basic understanding of natural selection. This first involves providing an overview of the basis and (one of the) general outcomes of natural selection as they are understood by evolutionary biologists ${ }^{1}$. This is followed by a brief discussion of the extent and possible causes of difficulties in fully grasping the concept and consequences of natural selection. Finally, a review of the most widespread misconceptions about natural selection is provided. It must be noted that specific instructional tools capable of creating deeper understanding among students generally have remained elusive, and no new suggestions along these lines are presented here. Rather, this article is aimed at readers who wish to confront and correct any misconceptions that they may harbor and/or to better recognize those held by most students and other non-specialists.

\section{The Basis and Basics of Natural Selection}

Though rudimentary forms of the idea had been presented earlier (e.g., Darwin and Wallace 1858 and several others before them), it was in On the Origin of Species by Means of Natural Selection that Darwin (1859) provided the first detailed exposition of the process and implications of natural selection ${ }^{2}$. According to Mayr (1982, 2001), Darwin's extensive discussion of natural selection can be distilled to five "facts" (i.e., direct observations) and three associated inferences. These are depicted in Fig. 1.

Some components of the process, most notably the sources of variation and the mechanisms of inheritance, were, due to the limited available information in Darwin's time, either vague or incorrect in his original formulation. Since then, each of the core aspects of the mechanism has been elucidated and well documented, making the modern theory $^{3}$ of natural selection far more detailed and vigorously supported than when first proposed 150 years ago. This updated understanding of natural selection consists of the elements outlined in the following sections.

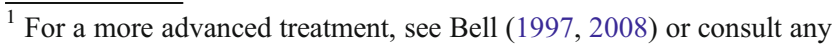
of the major undergraduate-level evolutionary biology or population genetics textbooks.

2 The Origin was, in Darwin's words, an "abstract" of a much larger work he had initially intended to write. Much of the additional material is available in Darwin (1868) and Stauffer (1975).

${ }^{3}$ See Gregory (2008a) for a discussion regarding the use of the term "theory" in science.
}

Overproduction, Limited Population Growth, and the "Struggle for Existence"

A key observation underlying natural selection is that, in principle, populations have the capacity to increase in numbers exponentially (or "geometrically"). This is a simple function of mathematics: If one organism produces two offspring, and each of them produces two offspring, and so on, then the total number grows at an increasingly rapid rate $\left(1 \rightarrow 2 \rightarrow 4 \rightarrow 8 \rightarrow 16 \rightarrow 32 \rightarrow 64 \ldots\right.$ to $2^{n}$ after $n$ rounds of reproduction).

The enormity of this potential for exponential growth is difficult to fathom. For example, consider that beginning with a single Escherichia coli bacterium, and assuming that cell division occurs every 30 minutes, it would take less than a week for the descendants of this one cell to exceed the mass of the Earth. Of course, exponential population expansion is not limited to bacteria. As Nobel laureate Jacques Monod once quipped, "What is true for $E$. coli is also true for the elephant," and indeed, Darwin (1859) himself used elephants as an illustration of the principle of rapid population growth, calculating that the number of descendants of a single pair would swell to more than $19,000,000$ in only 750 years ${ }^{4}$. Keown (1988) cites the example of oysters, which may produce as many as $114,000,000$ eggs in a single spawn. If all these eggs grew into oysters and produced this many eggs of their own that, in turn, survived to reproduce, then within five generations there would be more oysters than the number of electrons in the known universe.

Clearly, the world is not overrun with bacteria, elephants, or oysters. Though these and all other species engage in massive overproduction (or "superfecundity") and therefore could in principle expand exponentially, in practice they do not ${ }^{5}$. The reason is simple: Most offspring that are produced do not survive to produce offspring of their own. In fact, most population sizes tend to remain relatively stable over the long term. This necessarily means that, on average, each pair of oysters produces only two offspring that go on to reproduce successfully-and that $113,999,998$ eggs per female per spawn do not survive (see also Ridley 2004). Many young oysters will be eaten by predators, others will starve, and still others will succumb to infection. As Darwin (1859) realized, this massive discrepancy between the number of offspring produced

\footnotetext{
${ }^{4}$ Ridley (2004) points out that Darwin's calculations require overlapping generations to reach this exact number, but the point remains that even in slow-reproducing species the rate of potential production is enormous relative to actual numbers of organisms.

${ }^{5}$ Humans are currently undergoing a rapid population expansion, but this is the exception rather than the rule. As Darwin (1859) noted, "Although some species may now be increasing, more or less rapidly, in numbers, all cannot do so, for the world would not hold them."
} 
Fig. 1 The basis of natural selection as presented by Darwin (1859), based on the summary by Mayr (1982)

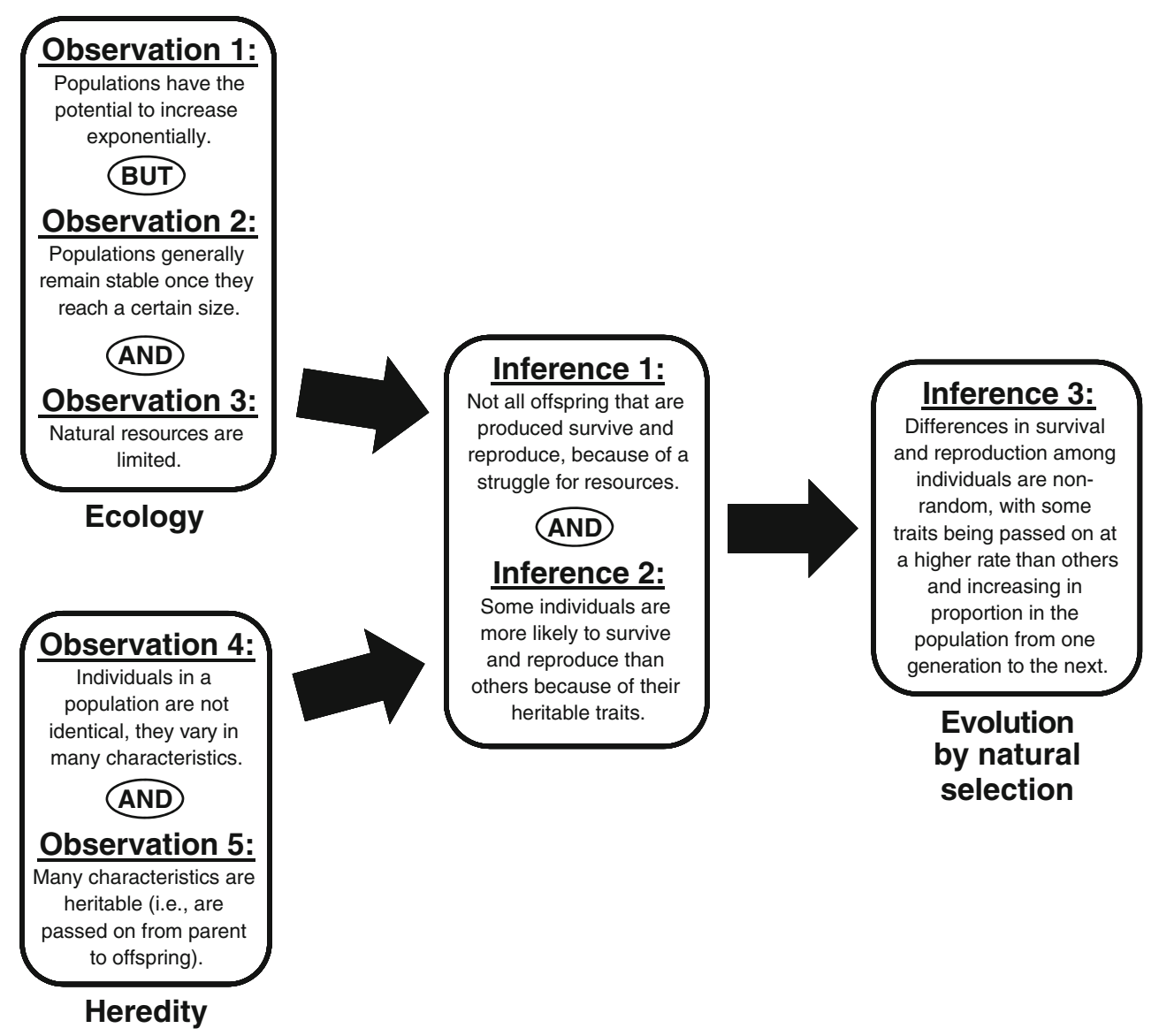

and the number that can be sustained by available resources creates a "struggle for existence" in which often only a tiny fraction of individuals will succeed. As he noted, this can be conceived as a struggle not only against other organisms (especially members of the same species, whose ecological requirements are very similar) but also in a more abstract sense between organisms and their physical environments.

Variation and Inheritance

Variation among individuals is a fundamental requirement for evolutionary change. Given that it was both critical to his theory of natural selection and directly counter to much contemporary thinking, it should not be surprising that Darwin (1859) expended considerable effort in attempting to establish that variation is, in fact, ubiquitous. He also emphasized the fact that some organisms - namely relatives, especially parents and their offspring-are more similar to each other than to unrelated members of the population. This, too, he realized is critical for natural selection to operate. As Darwin (1859) put it, "Any variation which is not inherited is unimportant for us." However, he could not explain either why variation existed or how specific characteristics were passed from parent to offspring, and therefore was forced to treat both the source of variation and the mechanism of inheritance as a "black box."

The workings of genetics are no longer opaque. Today, it is well understood that inheritance operates through the replication of DNA sequences and that errors in this process (mutations) and the reshuffling of existing variants (recombination) represent the sources of new variation. In particular, mutations are known to be random (or less confusingly, "undirected") with respect to any effects that they may have. Any given mutation is merely a chance error in the genetic system, and as such, its likelihood of occurrence is not influenced by whether it will turn out to be detrimental, beneficial, or (most commonly) neutral.

As Darwin anticipated, extensive variation among individuals has now been well established to exist at the physical, physiological, and behavioral levels. Thanks to the rise of molecular biology and, more recently, of genomics, it also has been possible to document variation at the level of proteins, genes, and even individual DNA nucleotides in humans and many other species.

Non-random Differences in Survival and Reproduction

Darwin saw that overproduction and limited resources create a struggle for existence in which some organisms 
will succeed and most will not. He also recognized that organisms in populations differ from one another in terms of many traits that tend to be passed on from parent to offspring. Darwin's brilliant insight was to combine these two factors and to realize that success in the struggle for existence would not be determined by chance, but instead would be biased by some of the heritable differences that exist among organisms. Specifically, he noted that some individuals happen to possess traits that make them slightly better suited to a particular environment, meaning that they are more likely to survive than individuals with less well suited traits. As a result, organisms with these traits will, on average, leave more offspring than their competitors.

Whereas the origin of a new genetic variant occurs at random in terms of its effects on the organism, the probability of it being passed on to the next generation is absolutely non-random if it impacts the survival and reproductive capabilities of that organism. The important point is that this is a two-step process: first, the origin of variation by random mutation, and second, the non-random sorting of variation due to its effects on survival and reproduction (Mayr 2001). Though definitions of natural selection have been phrased in many ways (Table 1), it is this non-random difference in survival and reproduction that forms the basis of the process.

\section{Darwinian Fitness}

The Meaning of Fitness in Evolutionary Biology

In order to study the operation and effects of natural selection, it is important to have a means of describing and quantifying the relationships between genotype (gene complement), phenotype (physical and behavioral features), survival, and reproduction in particular environments. The concept used by evolutionary biologists in this regard is known as "Darwinian fitness," which is defined most simply as a measure of the total (or relative) reproductive output of an organism with a particular genotype (Table 1). In the most basic terms, one can state that the more offspring an individual produces, the higher is its fitness. It must be emphasized that the term "fitness," as used in evolutionary biology, does not refer to physical condition, strength, or stamina and therefore differs markedly from its usage in common language.

\section{"Survival of the Fittest" is Misleading}

In the fifth edition of the Origin (published in 1869), Darwin began using the phrase "survival of the fittest", which had been coined a few years earlier by British economist Herbert Spencer, as shorthand for natural selection. This was an unfortunate decision as there are several reasons why "survival of the fittest" is a poor descriptor of natural selection. First, in Darwin's context, "fittest" implied "best suited to a particular environment" rather than "most physically fit," but this crucial distinction is often overlooked in non-technical usage (especially when further distorted to "only the strong survive"). Second, it places undue emphasis on survival: While it is true that dead organisms do not reproduce, survival is only important evolutionarily insofar as it affects the number of offspring produced. Traits that make life longer or less difficult are evolutionarily irrelevant unless they also influence reproductive output. Indeed, traits that enhance net reproduction may increase in frequency over many generations even if they compromise individual longevity. Conversely, differences in fecundity alone can create differences in fitness, even if survival rates are identical among individuals. Third, this implies an excessive focus on organisms, when in fact traits or their underlying genes equally can be identified as more or less fit than alternatives. Lastly, this phrase is often misconstrued as being circular or tautological (Who survives? The fittest. Who are the fittest? Those who survive). However, again, this misinterprets the modern meaning of fitness, which can be both predicted in terms of which traits are expected to be successful in a specific environment and measured in terms of actual reproductive success in that environment.

\section{Which Traits Are the Most Fit?}

Directional natural selection can be understood as a process by which fitter traits (or genes) increase in proportion within populations over the course of many generations. It must be understood that the relative fitness of different traits depends on the current environment. Thus, traits that are fit now may become unfit later if the environment changes. Conversely, traits that have now become fit may have been present long before the current environment arose, without having conferred any advantage under previous conditions. Finally, it must be noted that fitness refers to reproductive success relative to alternatives here and now-natural selection cannot increase the proportion of traits solely because they may someday become advantageous. Careful reflection on how natural selection actually works should make it clear why this is so.

\section{Natural Selection and Adaptive Evolution}

Natural Selection and the Evolution of Populations

Though each has been tested and shown to be accurate, none of the observations and inferences that underlies natural 
Table 1 Glossary definitions of "natural selection" and "fitness" from leading evolutionary textbooks

\begin{tabular}{lll}
\hline Reference Natural selection & Fitness
\end{tabular}

Ridley (2004)

Futuyma (2005)

Stearns and Hoekstra (2005)

Rose and Mueller (2006)

Barton et al. (2007)

Freeman and Herron (2007)

Hall and Hallgrimsson (2008)

Kardong (2008)
The process by which the forms of organisms in a population that are best adapted to the environment increase in frequency relative to less well-adapted forms over a number of generations

The differential survival and/or reproduction of classes of entities that differ in one or more characteristics. To constitute natural selection, the difference in survival and/or reproduction cannot be due to chance, and it must have the potential consequence of altering the proportions of the different entities. Thus, natural selection is also definable as a deterministic difference in the contribution of different classes of entities to subsequent generations. Usually, the differences are inherited. The entities may be alleles, genotypes or subsets of genotypes, populations, or, in the broadest sense, species. A complex concept

The correlation of a trait with variation in reproductive success

The differential net reproduction of genetically distinct entities, whether mobile genetic elements, organisms, demes, or entire species

The process by which genotypes with higher fitness increase in frequency in a population

A difference, on average, between the survival or fecundity of individuals with certain phenotypes compared with individuals with other phenotypes

Differential reproduction or survival of replicating organisms caused by agencies other than humans ${ }^{\mathrm{a}}$. Because such differential selective effects are widely prevalent and often act on hereditary (genetic) variations, natural selection is a common major cause for a change in the gene frequencies of a population that leads to a new distinctive genetic constitution (evolution)

The culling process by which individuals with beneficial traits survive and reproduce more frequently, on average, than individuals with less favorable traits
The average number of offspring produced by individuals with a certain genotype, relative to the number produced by individuals with other genotypes. When genotypes differ in fitness because of their effects on survival, fitness can be measured as the ratio of a genotype's frequency among the adults divided by its frequency among individuals at birth

The success of an entity in reproducing; hence, the average contribution of an allele or genotype to the next generation or to succeeding generations

Relative lifetime reproductive success, which includes the probability of surviving to reproduce. In certain situations, other measures are more appropriate. The most important modifications to this definition include the inclusion of the effects of age-specific reproduction and of density dependence

The average reproduction of an individual or genotype, calibrated over a complete life cycle

The number of offspring left by an individual after one generation. The fitness of an allele is the average fitness of individuals carrying that allele

The extent to which an individual contributes genes to future generations or an individual's score on a measure of performance expected to correlate with genetic contribution to future generations (such as lifetime reproductive success)

Central to evolutionary theory evaluating genotypes and populations, fitness has many definitions, ranging from comparing growth rates to comparing long-term survival rates. The basic fitness concept that population geneticists commonly use is relative reproductive success, as governed by selection in a particular environment

The relative reproductive success of individuals, within a population, in leaving offspring in the next generation. At the genetic level, fitness is measured by the relative success of one genotype (or allele) compared to other genotypes (or alleles)

\footnotetext{
a This means to draw a distinction between "natural selection" and "artificial selection," but the lines are not so clear (see Gregory 2009)
} 
selection is sufficient individually to provide a mechanism for evolutionary change ${ }^{6}$. Overproduction alone will have no evolutionary consequences if all individuals are identical. Differences among organisms are not relevant unless they can be inherited. Genetic variation by itself will not result in natural selection unless it exerts some impact on organism survival and reproduction. However, any time all of Darwin's postulates hold simultaneously - as they do in most populations - natural selection will occur. The net result in this case is that certain traits (or, more precisely, genetic variants that specify those traits) will, on average, be passed on from one generation to the next at a higher rate than existing alternatives in the population. Put another way, when one considers who the parents of the current generation were, it will be seen that a disproportionate number of them possessed traits beneficial for survival and reproduction in the particular environment in which they lived.

The important points are that this uneven reproductive success among individuals represents a process that occurs in each generation and that its effects are cumulative over the span of many generations. Over time, beneficial traits will become increasingly prevalent in descendant populations by virtue of the fact that parents with those traits consistently leave more offspring than individuals lacking those traits. If this process happens to occur in a consistent direction - say, the largest individuals in each generation tend to leave more offspring than smaller individuals - then there can be a gradual, generation-by-generation change in the proportion of traits in the population. This change in proportion and not the modification of organisms themselves is what leads to changes in the average value of a particular trait in the population. Organisms do not evolve; populations evolve.

\section{Adaptation}

The term "adaptation" derives from ad + aptus, literally meaning "toward + fit". As the name implies, this is the process by which populations of organisms evolve in such a way as to become better suited to their environments as advantageous traits become predominant. On a broader scale, it is also how physical, physiological, and behavioral features that contribute to survival and reproduction ("adaptations") arise over evolutionary time. This latter topic is particularly difficult for many to grasp, though of course a crucial first step is to understand the operation of natural selection on

\footnotetext{
${ }^{6}$ It cannot be overemphasized that "evolution" and "natural selection" are not interchangeable. This is because not all evolution occurs by natural selection and because not all outcomes of natural selection involve changes in the genetic makeup of populations. A detailed discussion of the different types of selection is beyond the scope of this article, but it can be pointed out that the effect of "stabilizing selection" is to prevent directional change in populations.
}

smaller scales of time and consequence. (For a detailed discussion of the evolution of complex organs such as eyes, see Gregory 2008b.)

On first pass, it may be difficult to see how natural selection can ever lead to the evolution of new characteristics if its primary effect is merely to eliminate unfit traits. Indeed, natural selection by itself is incapable of producing new traits, and in fact (as many readers will have surmised), most forms of natural selection deplete genetic variation within populations. How, then, can an eliminative process like natural selection ever lead to creative outcomes?

To answer this question, one must recall that evolution by natural selection is a two-step process. The first step involves the generation of new variation by mutation and recombination, whereas the second step determines which randomly generated variants will persist into the next generation. Most new mutations are neutral with respect to survival and reproduction and therefore are irrelevant in terms of natural selection (but not, it must be pointed out, to evolution more broadly). The majority of mutations that have an impact on survival and reproductive output will do so negatively and, as such, will be less likely than existing alternatives to be passed on to subsequent generations. However, a small percentage of new mutations will turn out to have beneficial effects in a particular environment and will contribute to an elevated rate of reproduction by organisms possessing them. Even a very slight advantage is sufficient to cause new beneficial mutations to increase in proportion over the span of many generations.

Biologists sometimes describe beneficial mutations as "spreading" or "sweeping" through a population, but this shorthand is misleading. Rather, beneficial mutations simply increase in proportion from one generation to the next because, by definition, they happen to contribute to the survival and reproductive success of the organisms carrying them. Eventually, a beneficial mutation may be the only alternative left as all others have ultimately failed to be passed on. At this point, that beneficial genetic variant is said to have become "fixed" in the population.

Again, mutation does not occur in order to improve fitness - it merely represents errors in genetic replication. This means that most mutations do not improve fitness: There are many more ways of making things worse than of making them better. It also means that mutations will continue to occur even after previous beneficial mutations have become fixed. As such, there can be something of a ratcheting effect in which beneficial mutations arise and become fixed by selection, only to be supplemented later by more beneficial mutations which, in turn, become fixed. All the while, neutral and deleterious mutations also occur in the population, the latter being passed on at a lower rate than alternatives and often being lost before reaching any appreciable frequency.

Of course, this is an oversimplification - in species with sexual reproduction, multiple beneficial mutations may be 
brought together by recombination such that the fixation of beneficial genes need not occur sequentially. Likewise, recombination can juxtapose deleterious mutations, thereby hastening their loss from the population. Nonetheless, it is useful to imagine the process of adaptation as one in which beneficial mutations arise continually (though perhaps very infrequently and with only minor positive impacts) and then accumulate in the population over many generations.

The process of adaptation in a population is depicted in very basic form in Fig. 2. Several important points can be drawn from even such an oversimplified rendition:

1. Mutations are the source of new variation. Natural selection itself does not create new traits; it only changes the proportion of variation that is already present in the population. The repeated two-step interaction of these processes is what leads to the evolution of novel adaptive features.

2. Mutation is random with respect to fitness. Natural selection is, by definition, non-random with respect to fitness. This means that, overall, it is a serious misconception to consider adaptation as happening "by chance".

3. Mutations occur with all three possible outcomes: neutral, deleterious, and beneficial. Beneficial mutations may be rare and deliver only a minor advantage, but these can nonetheless increase in proportion in the population over many generations by natural selection. The occurrence of any particular beneficial mutation

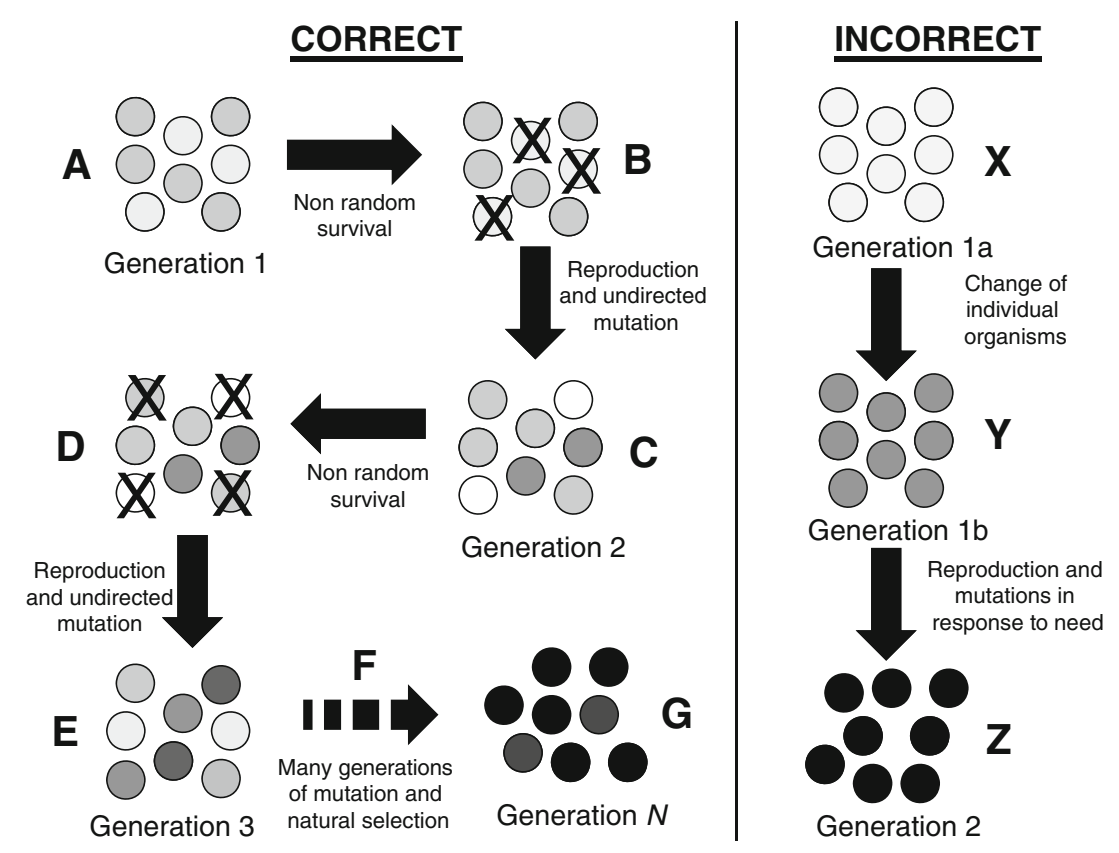

Fig. 2 A highly simplified depiction of natural selection (Correct) and a generalized illustration of various common misconceptions about the mechanism (Incorrect). Properly understood, natural selection occurs as follows: (A) A population of organisms exhibits variation in a particular trait that is relevant to survival in a given environment. In this diagram, darker coloration happens to be beneficial, but in another environment, the opposite could be true. As a result of their traits, not all individuals in Generation 1 survive equally well, meaning that only a non-random subsample ultimately will succeed in reproducing and passing on their traits $(B)$. Note that no individual organisms in Generation 1 change, rather the proportion of individuals with different traits changes in the population. The individuals who survive from Generation 1 reproduce to produce Generation 2. (C) Because the trait in question is heritable, this second generation will (mostly) resemble the parent generation. However, mutations have also occurred, which are undirected (i.e., they occur at random in terms of the consequences of changing traits), leading to both lighter and darker offspring in Generation 2 as compared to their parents in Generation 1. In this environment, lighter mutants are less successful and darker mutants are more successful than the parental average. Once again, there is non-random survival among individuals in the population, with darker traits becoming disproportionately common due to the death of lighter individuals $(D)$. This subset of Generation 2 proceeds to reproduce. Again, the traits of the survivors are passed on, but there is also undirected mutation leading to both deleterious and beneficial differences among the offspring $(E)$. $(F)$ This process of undirected mutation and natural selection (non-random differences in survival and reproductive success) occurs over many generations, each time leading to a concentration of the most beneficial traits in the next generation. By Generation $N$, the population is composed almost entirely of very dark individuals. The population can now be said to have become adapted to the environment in which darker traits are the most successful. This contrasts with the intuitive notion of adaptation held by most students and non-biologists. In the most common version, populations are seen as uniform, with variation being at most an anomalous deviation from the norm $(X)$. It is assumed that all members within a single generation change in response to pressures imposed by the environment $(Y)$. When these individuals reproduce, they are thought to pass on their acquired traits. Moreover, any changes that do occur due to mutation are imagined to be exclusively in the direction of improvement $(Z)$. Studies have revealed that it can be very difficult for non-experts to abandon this intuitive interpretation in favor of a scientifically valid understanding of the mechanism. Diagrams based in part on Bishop and Anderson (1990) 
may be very improbable, but natural selection is very effective at causing these individually unlikely improvements to accumulate. Natural selection is an improbability concentrator.

4. No organisms change as the population adapts. Rather, this involves changes in the proportion of beneficial traits across multiple generations.

5. The direction in which adaptive change occurs is dependent on the environment. A change in environment can make previously beneficial traits neutral or detrimental and vice versa.

6. Adaptation does not result in optimal characteristics. It is constrained by historical, genetic, and developmental limitations and by trade-offs among features (see Gregory 2008b).

7. It does not matter what an "ideal" adaptive feature might be - the only relevant factor is that variants that happen to result in greater survival and reproduction relative to alternative variants are passed on more frequently. As Darwin wrote in a letter to Joseph Hooker (11 Sept. 1857), "I have just been writing an audacious little discussion, to show that organic beings are not perfect, only perfect enough to struggle with their competitors."

8. The process of adaptation by natural selection is not forward-looking, and it cannot produce features on the grounds that they might become beneficial sometime in the future. In fact, adaptations are always to the conditions experienced by generations in the past.

\section{Natural Selection Is Elegant, Logical, and Notoriously Difficult to Grasp}

\section{The Extent of the Problem}

In its most basic form, natural selection is an elegant theory that effectively explains the obviously good fit of living things to their environments. As a mechanism, it is remarkably simple in principle yet incredibly powerful in application. However, the fact that it eluded description until 150 years ago suggests that grasping its workings and implications is far more challenging than is usually assumed.

Three decades of research have produced unambiguous data revealing a strikingly high prevalence of misconceptions about natural selection among members of the public and in students at all levels, from elementary school pupils to university science majors (Alters 2005; Bardapurkar 2008; Table 2) ${ }^{7}$. A finding that less than $10 \%$ of those surveyed

\footnotetext{
${ }^{7}$ Instructors interested in assessing their own students' level of understanding may wish to consult tests developed by Bishop and Anderson (1986), Anderson et al. (2002), Beardsley (2004), Shtulman (2006), or Kampourakis and Zogza (2009).
}

possess a functional understanding of natural selection is not atypical. It is particularly disconcerting and undoubtedly exacerbating that confusions about natural selection are common even among those responsible for teaching it ${ }^{8}$. As Nehm and Schonfeld (2007) recently concluded, "one cannot assume that biology teachers with extensive backgrounds in biology have an accurate working knowledge of evolution, natural selection, or the nature of science."

\section{Why is Natural Selection so Difficult to Understand?}

Two obvious hypotheses present themselves for why misunderstandings of natural selection are so widespread. The first is that understanding the mechanism of natural selection requires an acceptance of the historical fact of evolution, the latter being rejected by a large fraction of the population. While an improved understanding of the process probably would help to increase overall acceptance of evolution, surveys indicate that rates of acceptance already are much higher than levels of understanding. And, whereas levels of understanding and acceptance may be positively correlated among teachers (Vlaardingerbroek and Roederer 1997; Rutledge and Mitchell 2002; Deniz et al. 2008), the two parameters seem to be at most only very weakly related in students $^{9}$ (Bishop and Anderson 1990; Demastes et al. 1995; Brem et al. 2003; Sinatra et al. 2003; Ingram and Nelson 2006; Shtulman 2006). Teachers notwithstanding, "it appears that a majority on both sides of the evolution-creation debate do not understand the process of natural selection or its role in evolution" (Bishop and Anderson 1990).

The second intuitive hypothesis is that most people simply lack formal education in biology and have learned incorrect versions of evolutionary mechanisms from nonauthoritative sources (e.g., television, movies, parents). Inaccurate portrayals of evolutionary processes in the media, by teachers, and by scientists themselves surely exacerbate the situation (e.g., Jungwirth 1975a, b, 1977; Moore et al. 2002). However, this alone cannot provide a full explanation, because even direct instruction on natural selection tends to produce only modest improvements in students' understanding (e.g., Jensen and Finley 1995; Ferrari and Chi 1998; Nehm and Reilly 2007; Spindler and Doherty 2009). There also is evidence that levels of

\footnotetext{
${ }^{8}$ Even more alarming is a recent indication that one in six teachers in the USA is a young Earth creationist, and that about one in eight teaches creationism as though it were a valid alternative to evolutionary science (Berkman et al. 2008).

${ }^{9}$ Strictly speaking, it is not necessary to understand how evolution occurs to be convinced that it has occurred because the historical fact of evolution is supported by many convergent lines of evidence that are independent of discussions about particular mechanisms. Again, this represents the important distinction between evolution as fact and theory. See Gregory (2008a).
} 


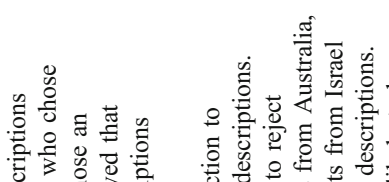

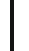

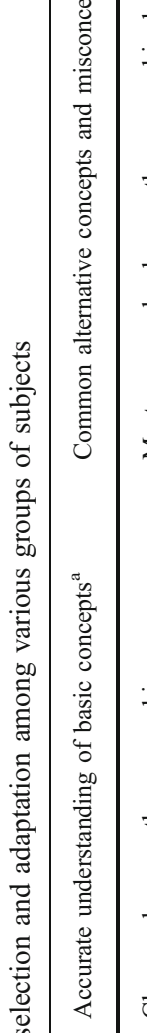

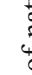

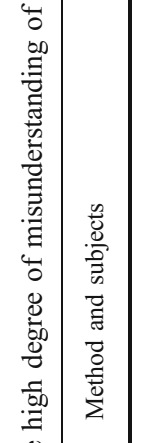

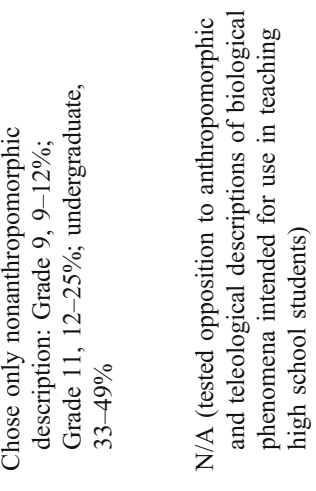

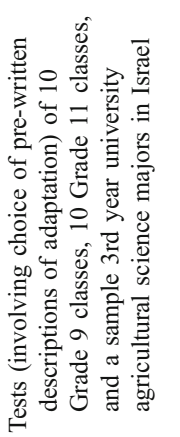

폰

产

을

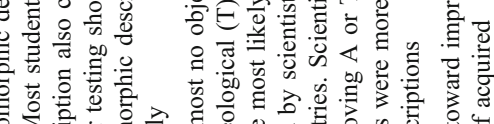

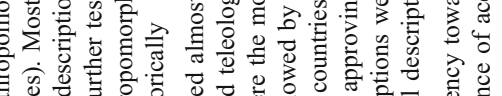

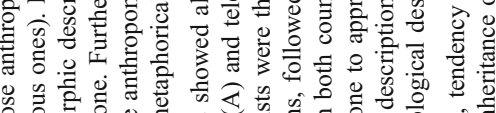

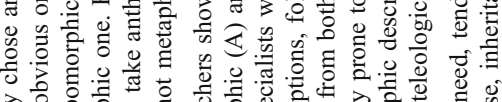

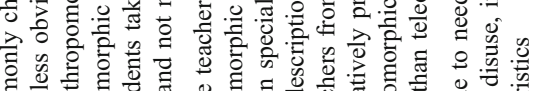

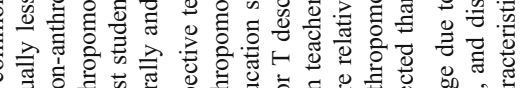

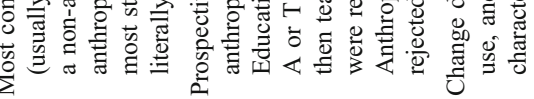

完矛

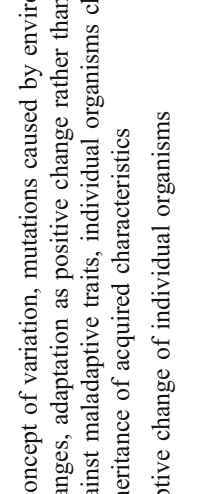

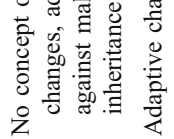
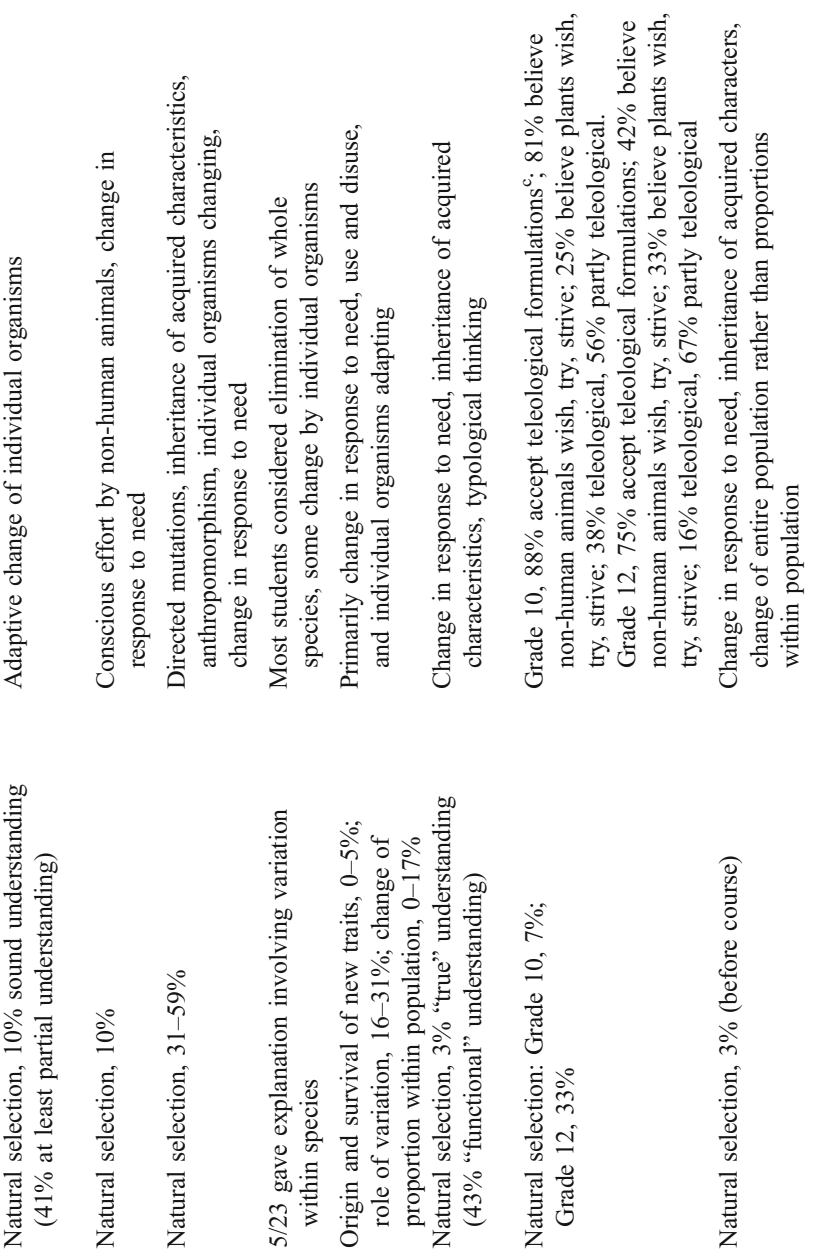

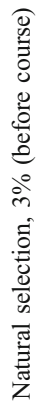

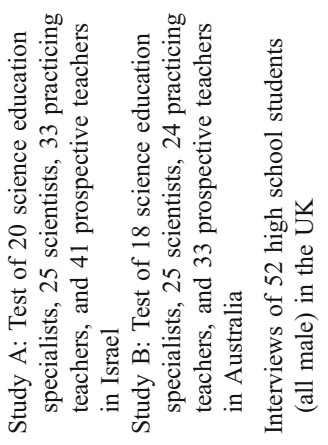

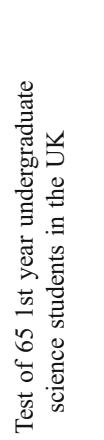
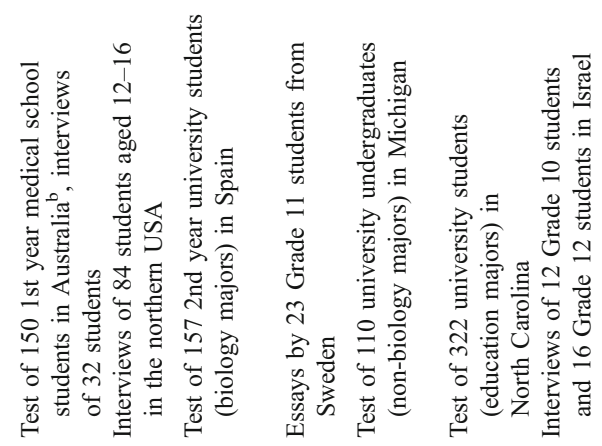

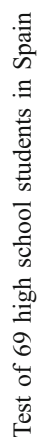

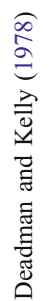
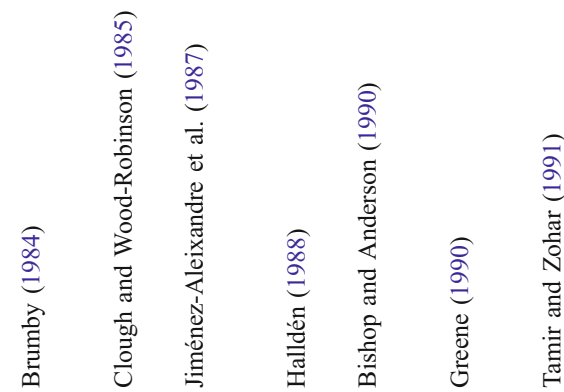

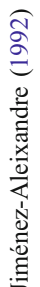



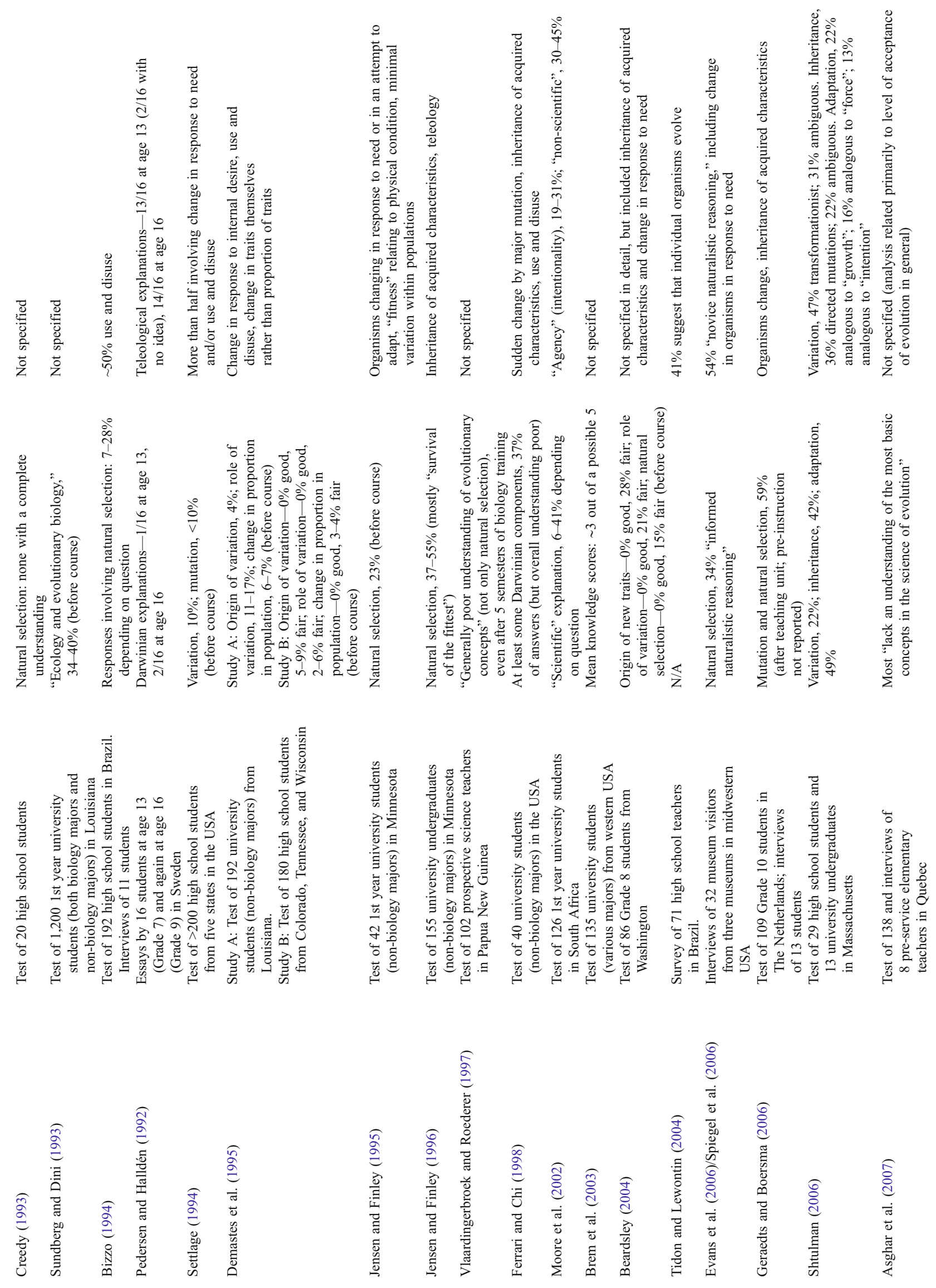


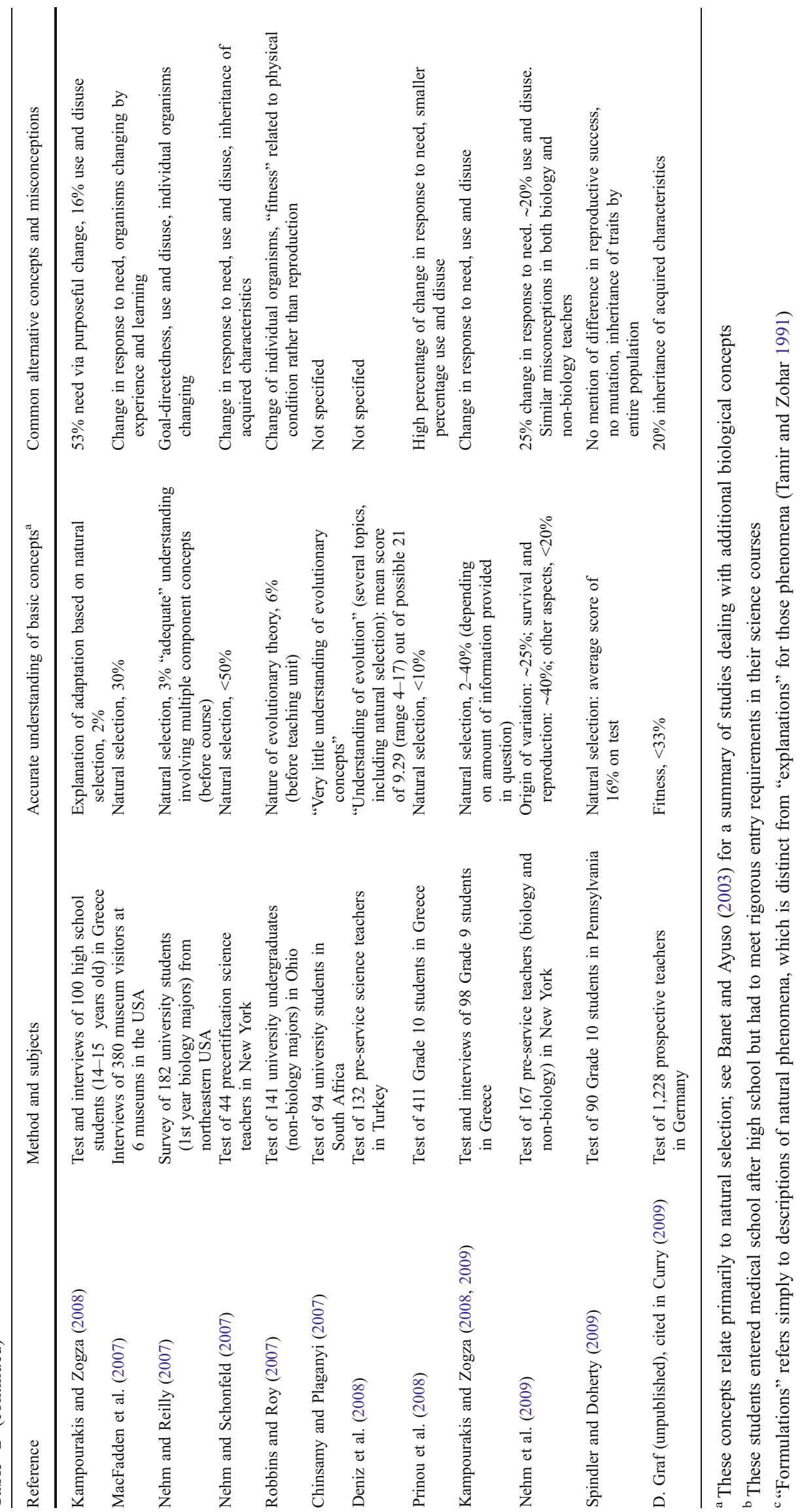


understanding do not differ greatly between science majors and non-science majors (Sundberg and Dini 1993). In the disquieting words of Ferrari and Chi (1998), "misconceptions about even the basic principles of Darwin's theory of evolution are extremely robust, even after years of education in biology."

Misconceptions are well known to be common with many (perhaps most) aspects of science, including much simpler and more commonly encountered phenomena such as the physics of motion (e.g., McCloskey et al. 1980; Halloun and Hestenes 1985; Bloom and Weisberg 2007). The source of this larger problem seems to be a significant disconnect between the nature of the world as reflected in everyday experience and the one revealed by systematic scientific investigation (e.g., Shtulman 2006; Sinatra et al. 2008). Intuitive interpretations of the world, though sufficient for navigating daily life, are usually fundamentally at odds with scientific principles. If common sense were more than superficially accurate, scientific explanations would be less counterintuitive, but they also would be largely unnecessary.

\section{Conceptual Frameworks Versus Spontaneous Constructions}

It has been suggested by some authors that young students simply are incapable of understanding natural selection because they have not yet developed the formal reasoning abilities necessary to grasp it (Lawson and Thompson 1988). This could be taken to imply that natural selection should not be taught until later grades; however, those who have studied student understanding directly tend to disagree with any such suggestion (e.g., Clough and Wood-Robinson 1985; Settlage 1994). Overall, the issue does not seem to be a lack of logic (Greene 1990; Settlage 1994), but a combination of incorrect underlying premises about mechanisms and deep-seated cognitive biases that influence interpretations.

Many of the misconceptions that block an understanding of natural selection develop early in childhood as part of "naïve" but practical understandings of how the world is structured. These tend to persist unless replaced with more accurate and equally functional information. In this regard, some experts have argued that the goal of education should be to supplant existing conceptual frameworks with more accurate ones (see Sinatra et al. 2008). Under this view, "Helping people to understand evolution...is not a matter of adding on to their existing knowledge, but helping them to revise their previous models of the world to create an entirely new way of seeing" (Sinatra et al. 2008). Other authors suggest that students do not actually maintain coherent conceptual frameworks relating to complex phenomena, but instead construct explanations spontaneously using intuitions derived from everyday experience (see Southerland et al. 2001). Though less widely accepted, this latter view gains support from the observation that naive evolutionary explanations given by non-experts may be tentative and inconsistent (Southerland et al. 2001) and may differ depending on the type of organisms being considered (Spiegel et al. 2006). In some cases, students may attempt a more complex explanation but resort to intuitive ideas when they encounter difficulty (Deadman and Kelly 1978). In either case, it is abundantly clear that simply describing the process of natural selection to students is ineffective and that it is imperative that misconceptions be confronted if they are to be corrected (e.g., Greene 1990; Scharmann 1990; Settlage 1994; Ferrari and Chi 1998; Alters and Nelson 2002; Passmore and Stewart 2002; Alters 2005; Nelson 2007).

\section{A Catalog of Common Misconceptions}

Whereas the causes of cognitive barriers to understanding remain to be determined, their consequences are well documented. It is clear from many studies that complex but accurate explanations of biological adaptation typically yield to naïve intuitions based on common experience (Fig. 2; Tables 2 and 3). As a result, each of the fundamental components of natural selection may be overlooked or misunderstood when it comes time to consider them in combination, even if individually they appear relatively straightforward. The following sections provide an overview of the various, non-mutually exclusive, and often correlated misconceptions that have been found to be most common. All readers are encouraged to consider these conceptual pitfalls carefully in order that they may be avoided. Teachers, in particular, are urged to familiarize themselves with these errors so that they may identify and address them among their students.

\section{Teleology and the "Function Compunction"}

Much of the human experience involves overcoming obstacles, achieving goals, and fulfilling needs. Not surprisingly, human psychology includes a powerful bias toward thoughts about the "purpose" or "function" of objects and behaviorswhat Kelemen and Rosset (2009) dub the "human function compunction." This bias is particularly strong in children, who are apt to see most of the world in terms of purpose; for example, even suggesting that "rocks are pointy to keep animals from sitting on them" (Kelemen 1999a, b; Kelemen and Rosset 2009). This tendency toward explanations based on purpose ("teleology") runs very deep and persists throughout high school (Southerland et al. 2001) and even into postsecondary education (Kelemen and Rosset 2009). In fact, it has been argued that the default mode of teleological thinking is, at best, suppressed rather than supplanted by introductory scientific education. It therefore reappears easily 
Table 3 Major concepts relating to adaptive evolution by natural selection, summarizing both correct and intuitive (incorrect) interpretations (see also Fig. 2)

\begin{tabular}{|c|c|c|}
\hline Concept & Correct interpretation & Intuitive (incorrect) interpretation \\
\hline $\begin{array}{l}\text { Existing variation among } \\
\text { individuals }\end{array}$ & $\begin{array}{l}\text { Common and important. A fundamental } \\
\text { requirement for evolutionary change }\end{array}$ & $\begin{array}{l}\text { Rare and/or unimportant. Deviation from "essence" } \\
\text { or "type" of the species. Not important in } \\
\text { evolutionary change }\end{array}$ \\
\hline Origin of new traits & $\begin{array}{l}\text { Arise in an undirected fashion by random } \\
\text { mutation. Some detrimental, some neutral, } \\
\text { some beneficial. Sorted according to effects } \\
\text { on organismal reproduction after they arise }\end{array}$ & $\begin{array}{l}\text { Arise in response to need. Always beneficial. } \\
\text { Offspring may exhibit new beneficial traits } \\
\text { even if the parents did not possess them. } \\
\text { The types of new traits that occur are determined } \\
\text { based on the environment }\end{array}$ \\
\hline Inheritance & $\begin{array}{l}\text { Traits are inherited from parents regardless } \\
\text { of whether they are beneficial or detrimental. } \\
\text { Physical changes in parents are not passed on. } \\
\text { Heritable differences between parents and } \\
\text { offspring are due to mutation and recombination }\end{array}$ & $\begin{array}{l}\text { Only beneficial traits are passed on. Beneficial } \\
\text { physical changes in parents are passed on to } \\
\text { offspring. Heritable differences between parents } \\
\text { and offspring are due to improvement in } \\
\text { response to needs }\end{array}$ \\
\hline Adaptation & $\begin{array}{l}\text { Due to non-random differences in survival and } \\
\text { reproduction among variable individuals over } \\
\text { many generations. Individual organisms themselves } \\
\text { do not change. The proportion of traits changes } \\
\text { from one generation to the next as some traits } \\
\text { are passed on at a higher rate than others }\end{array}$ & $\begin{array}{l}\text { Due to response to need or an effort to change } \\
\text { by individual organisms. Organisms change over } \\
\text { their lifetimes to become better able to survive } \\
\text { and pass these changes on to offspring. Any } \\
\text { differences between parent and offspring will be } \\
\text { in the direction of further improvement. The } \\
\text { entire species transforms in response to need }\end{array}$ \\
\hline
\end{tabular}

even in those with some basic scientific training; for example, in descriptions of ecological balance ("fungi grow in forests to help decomposition") or species survival ("finches diversified in order to survive"; Kelemen and Rosset 2009).

Teleological explanations for biological features date back to Aristotle and remain very common in naïve interpretations of adaptation (e.g., Tamir and Zohar 1991; Pedersen and Halldén 1992; Southerland et al. 2001; Sinatra et al. 2008; Table 2). On the one hand, teleological reasoning may preclude any consideration of mechanisms altogether if simply identifying a current function for an organ or behavior is taken as sufficient to explain its existence (e.g., Bishop and Anderson 1990). On the other hand, when mechanisms are considered by teleologically oriented thinkers, they are often framed in terms of change occurring in response to a particular need (Table 2). Obviously, this contrasts starkly with a two-step process involving undirected mutations followed by natural selection (see Fig. 2 and Table 3).

Anthropomorphism and Intentionality

A related conceptual bias to teleology is anthropomorphism, in which human-like conscious intent is ascribed either to the objects of natural selection or to the process itself (see below). In this sense, anthropomorphic misconceptions can be characterized as either internal (attributing adaptive change to the intentional actions of organisms) or external (conceiving of natural selection or "Nature" as a conscious agent; e.g., Kampourakis and Zogza 2008; Sinatra et al. 2008).

Internal anthropomorphism or "intentionality" is intimately tied to the misconception that individual organisms evolve in response to challenges imposed by the environment (rather than recognizing evolution as a populationlevel process). Gould (1980) described the obvious appeal of such intuitive notions as follows:

Since the living world is a product of evolution, why not suppose that it arose in the simplest and most direct way? Why not argue that organisms improve themselves by their own efforts and pass these advantages to their offspring in the form of altered genes - a process that has long been called, in technical parlance, the "inheritance of acquired characters." This idea appeals to common sense not only for its simplicity but perhaps even more for its happy implication that evolution travels an inherently progressive path, propelled by the hard work of organisms themselves.

The penchant for seeing conscious intent is often sufficiently strong that it is applied not only to nonhuman vertebrates (in which consciousness, though certainly not knowledge of genetics and Darwinian fitness, may actually occur), but also to plants and even to singlecelled organisms. Thus, adaptations in any taxon may be described as "innovations," "inventions," or "solutions" (sometimes "ingenious" ones, no less). Even the evolution of antibiotic resistance is characterized as a process 
whereby bacteria "learn" to "outsmart" antibiotics with frustrating regularity. Anthropomorphism with an emphasis on forethought is also behind the common misconception that organisms behave as they do in order to enhance the longterm well-being of their species. Once again, a consideration of the actual mechanics of natural selection should reveal why this is fallacious.

All too often, an anthropomorphic view of evolution is reinforced with sloppy descriptions by trusted authorities (Jungwirth 1975a, b, 1977; Moore et al. 2002). Consider this particularly egregious example from a website maintained by the National Institutes of Health ${ }^{10}$ :

As microbes evolve, they adapt to their environment. If something stops them from growing and spreading — such as an antimicrobial- they evolve new mechanisms to resist the antimicrobials by changing their genetic structure. Changing the genetic structure ensures that the offspring of the resistant microbes are also resistant.

Fundamentally inaccurate descriptions such as this are alarmingly common. As a corrective, it is a useful exercise to translate such faulty characterizations into accurate language ${ }^{11}$. For example, this could read:

Bacteria that cause disease exist in large populations, and not all individuals are alike. If some individuals happen to possess genetic features that make them resistant to antibiotics, these individuals will survive the treatment while the rest gradually are killed off. As a result of their greater survival, the resistant individuals will leave more offspring than susceptible individuals, such that the proportion of resistant individuals will increase each time a new generation is produced. When only the descendants of the resistant individuals are left, the population of bacteria can be said to have evolved resistance to the antibiotics.

\section{Use and Disuse}

Many students who manage to avoid teleological and anthropomorphic pitfalls nonetheless conceive of evolution as involving change due to use or disuse of organs. This view, which was developed explicitly by Jean-Baptiste

\footnotetext{
$\overline{{ }^{10} \mathrm{http} / / / \mathrm{www} 3}$.niaid.nih.gov/topics/antimicrobialResistance/Under standing/history.htm, accessed February 2009.

${ }^{11}$ One should always be wary of the linguistic symptoms of anthropomorphic misconceptions, which usually include phrasing like "so that" (versus "because") or "in order to" (versus "happened to") when explaining adaptations (Kampourakis and Zogza 2009).
}

Lamarck but was also invoked to an extent by Darwin (1859), emphasizes changes to individual organisms that occur as they use particular features more or less. For example, Darwin (1859) invoked natural selection to explain the loss of sight in some subterranean rodents, but instead favored disuse alone as the explanation for loss of eyes in blind, cave-dwelling animals: "As it is difficult to imagine that eyes, though useless, could be in any way injurious to animals living in darkness, I attribute their loss wholly to disuse." This sort of intuition remains common in naïve explanations for why unnecessary organs become vestigial or eventually disappear. Modern evolutionary theory recognizes several reasons that may account for the loss of complex features (e.g., Jeffery 2005; Espinasa and Espinasa 2008), some of which involve direct natural selection, but none of which is based simply on disuse.

\section{Soft Inheritance}

Evolution involving changes in individual organisms, whether based on conscious choice or use and disuse, would require that characteristics acquired during the lifetime of an individual be passed on to offspring ${ }^{12}$, a process often termed "soft inheritance." The notion that acquired traits can be transmitted to offspring remained a common assumption among thinkers for more than 2,000 years, including into Darwin's time (Zirkle 1946). As is now understood, inheritance is actually "hard," meaning that physical changes that occur during an organism's lifetime are not passed to offspring. This is because the cells that are involved in reproduction (the germline) are distinct from those that make up the rest of the body (the somatic line); only changes that affect the germline can be passed on. New genetic variants arise through mutation and recombination during replication and will often only exert their effects in offspring and not in

\footnotetext{
${ }^{12}$ It must be noted that the persistent tendency to label the inheritance of acquired characteristics as "Lamarckian" is false: Soft inheritance was commonly accepted long before Lamarck's time (Zirkle 1946). Likewise, mechanisms involving organisms' conscious desires to change are often incorrectly attributed to Lamarck. For recent critiques of the tendency to describe various misconceptions as Lamarckian, see Geraedts and Boersma (2006) and Kampourakis and Zogza (2007). It is unfortunate that these mistakenly attributed concepts serve as the primary legacy of Lamarck, who in actuality made several important contributions to biology (a term first used by Lamarck), including greatly advancing the classification of invertebrates (another term he coined) and, of course, developing the first (albeit ultimately incorrect) mechanistic theory of evolution. For discussions of Lamarck's views and contributions to evolutionary biology, see Packard (1901), Burkhardt (1972, 1995), Corsi (1988), Humphreys (1995, 1996), and Kampourakis and Zogza (2007). Lamarck's works are available online at http://www.lamarck.cnrs.fr/index.php?lang=en.
} 
the parents in whose reproductive cells they occur (though they could also arise very early in development and appear later in the adult offspring). Correct and incorrect interpretations of inheritance are contrasted in Fig. 3.

Studies have indicated that belief in soft inheritance arises early in youth as part of a naïve model of heredity (e.g., Deadman and Kelly 1978; Kargbo et al. 1980; Lawson and Thompson 1988; Wood-Robinson 1994). That it seems intuitive probably explains why the idea of soft inheritance persisted so long among prominent thinkers and why it is so resistant to correction among modern students. Unfortunately, a failure to abandon this belief is fundamentally incompatible with an appreciation of evolution by natural selection as a two-step process in which the origin of new variation and its relevance to survival in a particular environment are independent considerations.

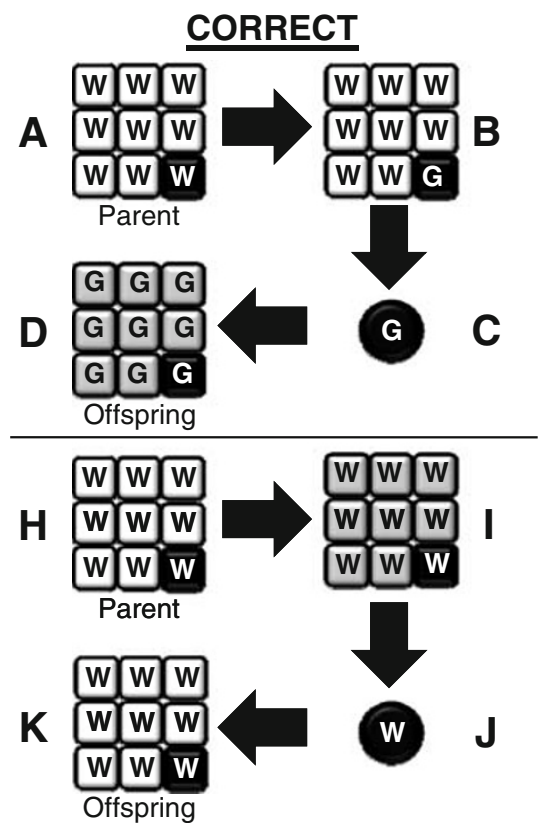

Fig. 3 A summary of correct (left) and incorrect (right) conceptions of heredity as it pertains to adaptive evolutionary change. The panels on the left display the operation of "hard inheritance", whereas those on the right illustrate naive mechanisms of "soft inheritance". In all diagrams, a set of nine squares represents an individual multicellular organism and each square represents a type of cell of which the organisms are constructed. In the left panels, the organisms include two kinds of cells: those that produce gametes (the germline, black) and those that make up the rest of the body (the somatic line, white). In the top left panel, all cells in a parent organism initially contain a gene that specifies white coloration, marked $W(A)$. A random mutation occurs in the germline, changing the gene from one that specifies white to one that specifies gray, marked $G(B)$. This mutant gene is passed to the egg $(C)$, which then develops into an offspring exhibiting gray coloration $(D)$. The mutation in this case occurred in the parent (specifically, in the germline) but its effects did not become apparent until the next generation. In the bottom left panel, a parent once again begins with white coloration and the white gene in all of its cells $(H)$. During its lifetime, the parent comes to acquire a gray coloration due to exposure to particular environmental conditions $(I)$.
Nature as a Selecting Agent

Thirty years ago, widely respected broadcaster Sir David Attenborough (1979) aptly described the challenge of avoiding anthropomorphic shorthand in descriptions of adaptation:

Darwin demonstrated that the driving force of [adaptive] evolution comes from the accumulation, over countless generations, of chance genetical changes sifted by the rigors of natural selection. In describing the consequences of this process it is only too easy to use a form of words that suggests that the animals themselves were striving to bring about change in a purposeful way-that fish wanted to climb onto dry land, and to modify their fins into legs, that reptiles wished to fly, strove to change their scales into feathers and so ultimately became birds.

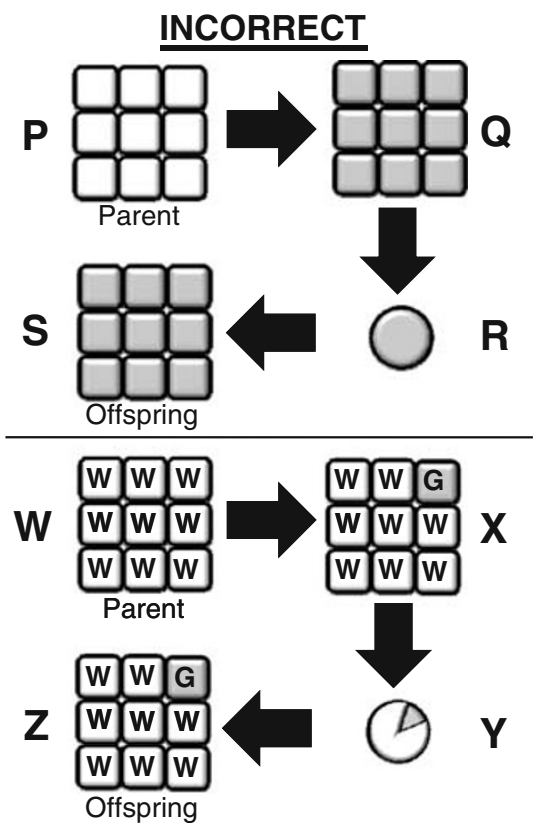

However, because this does not involve any change to the genes in the germline, the original white gene is passed into the egg $(J)$, and the offspring exhibits none of the gray coloration that was acquired by its parent $(K)$. In the top right panel, the distinction between germline and somatic line is not understood. In this case, a parent that initially exhibits white coloration $(P)$ changes during its lifetime to become gray $(Q)$. Under incorrect views of soft inheritance, this altered coloration is passed on to the egg $(R)$, and the offspring is born with the gray color acquired by its parent $(S)$. In the bottom right panel, a more sophisticated but still incorrect view of inheritance is shown. Here, traits are understood to be specified by genes, but no distinction is recognized between the germline and somatic line. In this situation, a parent begins with white coloration and white-specifying genes in all its cells $(W)$. A mutation occurs in one type of body cells to change those cells to gray $(X)$. A mixture of white and gray genes is passed on to the egg $(Y)$, and the offspring develops white coloration in most cells but gray coloration in the cells where gray-inducing mutations arose in the parent $(Z)$. Intuitive ideas regarding soft inheritance underlie many misconceptions of how adaptive evolution takes place (see Fig. 2) 
Unlike many authors, Attenborough (1979) admirably endeavored to not use such misleading terminology. However, this quote inadvertently highlights an additional challenge in describing natural selection without loaded language. In it, natural selection is described as a "driving force" that rigorously "sifts" genetic variation, which could be misunderstood to imply that it takes an active role in prompting evolutionary change. Much more seriously, one often encounters descriptions of natural selection as a processes that "chooses" among "preferred" variants or "experiments with" or "explores" different options. Some expressions, such as "favored" and "selected for" are used commonly as shorthand in evolutionary biology and are not meant to impart consciousness to natural selection; however, these too may be misinterpreted in the vernacular sense by non-experts and must be clarified.

Darwin (1859) himself could not resist slipping into the language of agency at times:

It may be said that natural selection is daily and hourly scrutinizing, throughout the world, every variation, even the slightest; rejecting that which is bad, preserving and adding up all that is good; silently and insensibly working, whenever and wherever opportunity offers, at the improvement of each organic being in relation to its organic and inorganic conditions of life. We see nothing of these slow changes in progress, until the hand of time has marked the long lapse of ages, and then so imperfect is our view into long past geological ages, that we only see that the forms of life are now different from what they formerly were.

Perhaps recognizing the ease with which such language can be misconstrued, Darwin (1868) later wrote that "The term 'Natural Selection' is in some respects a bad one, as it seems to imply conscious choice; but this will be disregarded after a little familiarity." Unfortunately, more than "a little familiarity" seems necessary to abandon the notion of Nature as an active decision maker.

Being, as it is, the simple outcome of differences in reproductive success due to heritable traits, natural selection cannot have plans, goals, or intentions, nor can it cause changes in response to need. For this reason, Jungwirth (1975a, b, 1977) bemoaned the tendency for authors and instructors to invoke teleological and anthropomorphic descriptions of the process and argued that this served to reinforce misconceptions among students (see also Bishop and Anderson 1990; Alters and Nelson 2002; Moore et al. 2002; Sinatra et al. 2008). That said, a study of high school students by Tamir and Zohar (1991) suggested that older students can recognize the distinction between an anthropomorphic or teleological formulation (i.e., merely a convenient description) versus an anthropomorphic/teleological explanation (i.e., involving conscious intent or goal-oriented mechanisms as causal factors; see also Bartov 1978, 1981). Moore et al. (2002), by contrast, concluded from their study of undergraduates that "students fail to distinguish between the relatively concrete register of genetics and the more figurative language of the specialist shorthand needed to condense the long view of evolutionary processes" (see also Jungwirth 1975a, 1977). Some authors have argued that teleological wording can have some value as shorthand for describing complex phenomena in a simple way precisely because it corresponds to normal thinking patterns, and that contrasting this explicitly with accurate language can be a useful exercise during instruction (Zohar and Ginossar 1998). In any case, biologists and instructors should be cognizant of the risk that linguistic shortcuts may send students off track.

\section{Source Versus Sorting of Variation}

Intuitive models of evolution based on soft inheritance are onestep models of adaptation: Traits are modified in one generation and appear in their altered form in the next. This is in conflict with the actual two-step process of adaptation involving the independent processes of mutation and natural selection. Unfortunately, many students who eschew soft inheritance nevertheless fail to distinguish natural selection from the origin of new variation (e.g., Greene 1990; Creedy 1993; Moore et al. 2002). Whereas an accurate understanding recognizes that most new mutations are neutral or harmful in a given environment, such naïve interpretations assume that mutations occur as a response to environmental challenges and therefore are always beneficial (Fig. 2). For example, many students may believe that exposure to antibiotics directly causes bacteria to become resistant, rather than simply changing the relative frequencies of resistant versus non-resistant individuals by killing off the latter ${ }^{13}$. Again, natural selection itself does not create new variation, it merely influences the proportion of existing variants. Most forms of selection reduce the amount of genetic variation within populations, which may be counteracted by the continual emergence of new variation via undirected mutation and recombination.

Typological, Essentialist, and Transformationist Thinking

Misunderstandings about how variation arises are problematic, but a common failure to recognize that it plays a role at all represents an even a deeper concern. Since Darwin (1859), evolutionary theory has been based strongly on "population"

\footnotetext{
$\overline{13}$ One may wonder how this misconception is reconciled with the common admonition by medical doctors to complete each course of treatment with antibiotics even after symptoms disappear-would this not provide more opportunities for bacteria to "develop" resistance by prolonging exposure?
} 
thinking that emphasizes differences among individuals. By contrast, many naïve interpretations of evolution remain rooted in the "typological" or "essentialist" thinking that has existed since the ancient Greeks (Mayr 1982, 2001; Sinatra et al. 2008). In this case, species are conceived of as exhibiting a single "type" or a common "essence," with variation among individuals representing anomalous and largely unimportant deviations from the type or essence. As Shtulman (2006) notes, "human beings tend to essentialize biological kinds and essentialism is incompatible with natural selection." As with many other conceptual biases, the tendency to essentialize seems to arise early in childhood and remains the default for most individuals (Strevens 2000; Gelman 2004; Evans et al. 2005; Shtulman 2006).

The incorrect belief that species are uniform leads to "transformationist" views of adaptation in which an entire population transforms as a whole as it adapts (Alters 2005; Shtulman 2006; Bardapurkar 2008). This contrasts with the correct, "variational" understanding of natural selection in which it is the proportion of traits within populations that changes (Fig. 2). Not surprisingly, transformationist models of adaptation usually include a tacit assumption of soft inheritance and one-step change in response to challenges. Indeed, Shtulman (2006) found that transformationists appeal to "need" as a cause of evolutionary change three times more often than do variationists.

\section{Events and Absolutes Versus Processes and Probabilities}

A proper understanding of natural selection recognizes it as a process that occurs within populations over the course of many generations. It does so through cumulative, statistical effects on the proportion of traits differing in their consequences for reproductive success. This contrasts with two major errors that are commonly incorporated into naïve conceptions of the process:

1. Natural selection is mistakenly seen as an event rather than as a process (Ferrari and Chi 1998; Sinatra et al. 2008). Events generally have a beginning and end, occur in a specific sequential order, consist of distinct actions, and may be goal-oriented. By contrast, natural selection actually occurs continually and simultaneously within entire populations and is not goal-oriented (Ferrari and Chi 1998). Misconstruing selection as an event may contribute to transformationist thinking as adaptive changes are thought to occur in the entire population simultaneously. Viewing natural selection as a single event can also lead to incorrect "saltationist" assumptions in which complex adaptive features are imagined to appear suddenly in a single generation (see Gregory 2008b for an overview of the evolution of complex organs).
2. Natural selection is incorrectly conceived as being "all or nothing," with all unfit individuals dying and all fit individuals surviving. In actuality, it is a probabilistic process in which some traits make it more likely-but do not guarantee - that organisms possessing them will successfully reproduce. Moreover, the statistical nature of the process is such that even a small difference in reproductive success (say, 1\%) is enough to produce a gradual increase in the frequency of a trait over many generations.

\section{Concluding Remarks}

Surveys of students at all levels paint a bleak picture regarding the level of understanding of natural selection. Though it is based on well-established and individually straightforward components, a proper grasp of the mechanism and its implications remains very rare among non-specialists. The unavoidable conclusion is that the vast majority of individuals, including most with postsecondary education in science, lack a basic understanding of how adaptive evolution occurs.

While no concrete solutions to this problem have yet been found, it is evident that simply outlining the various components of natural selection rarely imparts an understanding of the process to students. Various alternative teaching strategies and activities have been suggested, and some do help to improve the level of understanding among students (e.g., Bishop and Anderson 1986; Jensen and Finley 1995, 1996; Firenze 1997; Passmore and Stewart 2002; Sundberg 2003; Alters 2005; Scharmann 1990; Wilson 2005; Nelson 2007, 2008; Pennock 2007; Kampourakis and Zogza 2008). Efforts to integrate evolution throughout biology curricula rather than segregating it into a single unit may also prove more effective (Nehm et al. 2009), as may steps taken to make evolution relevant to everyday concerns (e.g., Hillis 2007).

At the very least, it is abundantly clear that teaching and learning natural selection must include efforts to identify, confront, and supplant misconceptions. Most of these derive from deeply held conceptual biases that may have been present since childhood. Natural selection, like most complex scientific theories, runs counter to common experience and therefore competes-usually unsuccessfully-with intuitive ideas about inheritance, variation, function, intentionality, and probability. The tendency, both outside and within academic settings, to use inaccurate language to describe evolutionary phenomena probably serves to reinforce these problems.

Natural selection is a central component of modern evolutionary theory, which in turn is the unifying theme of all biology. Without a grasp of this process and its con- 
sequences, it is simply impossible to understand, even in basic terms, how and why life has become so marvelously diverse. The enormous challenge faced by biologists and educators in correcting the widespread misunderstanding of natural selection is matched only by the importance of the task.

\section{References}

Alters B. Teaching biological evolution in higher education. Boston: Jones and Bartlett; 2005.

Alters BJ, Nelson CE. Teaching evolution in higher education. Evolution. 2002;56:1891-901.

Anderson DL, Fisher KM, Norman GJ. Development and evaluation of the conceptual inventory of natural selection. J Res Sci Teach. 2002;39:952-78. doi:10.1002/tea.10053.

Asghar A, Wiles JR, Alters B. Canadian pre-service elementary teachers' conceptions of biological evolution and evolution education. McGill J Educ. 2007;42:189-209.

Attenborough D. Life on earth. Boston: Little, Brown and Company; 1979.

Banet E, Ayuso GE. Teaching of biological inheritance and evolution of living beings in secondary school. Int J Sci Edu 2003;25: 373-407.

Bardapurkar A. Do students see the "selection" in organic evolution? A critical review of the causal structure of student explanations. Evo Edu Outreach. 2008;1:299-305. doi:10.1007/s12052-008-0048-5.

Barton NH, Briggs DEG, Eisen JA, Goldstein DB, Patel NH. Evolution. Cold Spring Harbor: Cold Spring Harbor Laboratory Press; 2007.

Bartov H. Can students be taught to distinguish between teleological and causal explanations? J Res Sci Teach. 1978;15:567-72. doi:10.1002/tea.3660150619.

Bartov H. Teaching students to understand the advantages and disadvantages of teleological and anthropomorphic statements in biology. J Res Sci Teach. 1981;18:79-86. doi:10.1002/tea.3660180113.

Beardsley PM. Middle school student learning in evolution: are current standards achievable? Am Biol Teach. 2004;66:604-12. doi:10.1662/0002-7685(2004)066[0604:MSSLIE]2.0.CO;2.

Bell G. The basics of selection. New York: Chapman \& Hall; 1997.

Bell G. Selection: the mechanism of evolution. 2nd ed. Oxford: Oxford University Press; 2008.

Berkman MB, Pacheco JS, Plutzer E. Evolution and creationism in America's classrooms: a national portrait. PLoS Biol. 2008;6: e124. doi:10.1371/journal.pbio.0060124.

Bishop BA, Anderson CW. Evolution by natural selection: a teaching module (Occasional Paper No. 91). East Lansing: Institute for Research on Teaching; 1986.

Bishop BA, Anderson CW. Student conceptions of natural selection and its role in evolution. J Res Sci Teach. 1990;27:415-27. doi:10.1002/tea.3660270503.

Bizzo NMV. From Down House landlord to Brazilian high school students: what has happened to evolutionary knowledge on the way? J Res Sci Teach. 1994;31:537-56.

Bloom P, Weisberg DS. Childhood origins of adult resistance to science. Science. 2007;316:996-7. doi:10.1126/science.1133398.

Brem SK, Ranney M, Schindel J. Perceived consequences of evolution: college students perceive negative personal and social impact in evolutionary theory. Sci Educ. 2003;87:181-206. doi: $10.1002 /$ sce. 10105 .

Brumby M. Problems in learning the concept of natural selection. J Biol Educ. 1979;13:119-22.

Brumby MN. Misconceptions about the concept of natural selection by medical biology students. Sci Educ. 1984;68:493-503. doi:10.1002/sce.3730680412.
Burkhardt RW. The inspiration of Lamarck's belief in evolution. J Hist Biol. 1972;5:413-38. doi:10.1007/BF00346666.

Burkhardt RW. The spirit of system. Cambridge: Harvard University Press; 1995.

Chinsamy A, Plaganyi E. Accepting evolution. Evolution. 2007; 62:248-54.

Clough EE, Wood-Robinson C. How secondary students interpret instances of biological adaptation. J Biol Educ. 1985;19:125-30.

Corsi P. The age of Lamarck. Berkeley: University of California Press; 1988.

Coyne JA. Selling Darwin. Nature. 2006;442:983-4. doi:10.1038/ 442983a.

Creedy LJ. Student understanding of natural selection. Res Sci Educ. 1993;23:34-41. doi:10.1007/BF02357042.

Curry A. Creationist beliefs persist in Europe. Science. 2009;323:1159. doi:10.1126/science.323.5918.1159.

Darimont CT, Carlson SM, Kinnison MT, Paquet PC, Reimchen TE, Wilmers CC. Human predators outpace other agents of trait change in the wild. Proc Natl Acad Sci U S A. 2009;106:952-4. doi:10.1073/pnas.0809235106.

Darwin C. On the origin of species by means of natural selection, or the preservation of favoured races in the struggle for life. London: John Murray; 1859.

Darwin, C. The variation of animals and plants under domestication. London: John Murray; 1868.

Darwin C, Wallace AR. On the tendency of species to form varieties; and on the perpetuation of varieties and species by natural means of selection. Proc Linn Soc. 1858;3:46-62.

Deadman JA, Kelly PJ. What do secondary school boys understand about evolution and heredity before they are taught the topic? J Biol Educ. 1978;12:7-15.

Demastes SS, Settlage J, Good R. Students' conceptions of natural selection and its role in evolution: cases of replication and comparison. J Res Sci Teach. 1995;32:535-50. doi:10.1002/ tea.3660320509.

Deniz H, Donelly LA, Yilmaz I. Exploring the factors related to acceptance of evolutionary theory among Turkish preservice biology teachers: toward a more informative conceptual ecology for biological evolution. J Res Sci Teach. 2008;45:420-43. doi:10.1002/tea.20223.

Dennett DC. Darwin's dangerous idea. New York: Touchstone Books; 1995.

Espinasa M, Espinasa L. Losing sight of regressive evolution. Evo Edu Outreach. 2008;1:509-16. doi:10. 1007/s12052-008-0094-z.

Evans EM, Mull MS, Poling DA, Szymanowski K. Overcoming an essentialist bias: from metamorphosis to evolution. In Biennial meeting of the Society for Research in Child Development, Atlanta, GA; 2005.

Evans EM, Spiegel A, Gram W, Frazier BF, Thompson S, Tare M, Diamond J. A conceptual guide to museum visitors' understanding of evolution. In Annual Meeting of the American Education Research Association, San Francisco; 2006.

Ferrari M, Chi MTH. The nature of naive explanations of natural selection. Int J Sci Educ. 1998;20:1231-56. doi:10.1080/ 0950069980201005.

Firenze R. Lamarck vs. Darwin: dueling theories. Rep Natl Cent Sci Educ. 1997;17:9-11.

Freeman S, Herron JC. Evolutionary analysis. 4th ed. Upper Saddle River: Prentice Hall; 2007.

Futuyma DJ. Evolution. Sunderland: Sinauer; 2005.

Gelman SA. Psychological essentialism in children. Trends Cogn Sci. 2004;8:404-9. doi:10.1016/j.tics.2004.07.001.

Geraedts CL, Boersma KT. Reinventing natural selection. Int J Sci Educ. 2006;28:843-70. doi:10.1080/09500690500404722.

Gould SJ. Shades of Lamarck. In: The Panda's Thumb. New York: Norton; 1980. p. 76-84. 
Greene ED. The logic of university students' misunderstanding of natural selection. J Res Sci Teach. 1990;27:875-85. doi:10.1002/ tea.3660270907.

Gregory TR. Evolution as fact, theory, and path. Evo Edu Outreach. 2008a;1:46-52. doi:10.1007/s12052-007-0001-z.

Gregory TR. The evolution of complex organs. Evo Edu Outreach. 2008b;1:358-89. doi:10.1007/s12052-008-0076-1.

Gregory TR. Artificial selection and domestication: modern lessons from Darwin's enduring analogy. Evo Edu Outreach. 2009;2:527. doi:10.1007/s12052-008-0114-z.

Hall BK, Hallgrimsson B. Strickberger's evolution. 4th ed. Sudbury: Jones and Bartlett; 2008

Halldén $\mathrm{O}$. The evolution of the species: pupil perspectives and school perspectives. Int J Sci Educ. 1988;10:541-52. doi:10.1080/ 0950069880100507

Halloun IA, Hestenes D. The initial knowledge state of college physics students. Am J Phys. 1985;53:1043-55. doi:10.1119/1.14030.

Hillis DM. Making evolution relevant and exciting to biology students. Evolution. 2007;61:1261-4. doi:10.1111/j.1558-5646. 2007.00126.x.

Humphreys J. The laws of Lamarck. Biologist. 1995;42:121-5.

Humphreys J. Lamarck and the general theory of evolution. J Biol Educ. 1996;30:295-303.

Ingram EL, Nelson CE. Relationship between achievement and students' acceptance of evolution or creation in an upper-level evolution course. J Res Sci Teach. 2006;43:7-24. doi:10.1002/ tea.20093.

Jeffery WR. Adaptive evolution of eye degeneration in the Mexican blind cavefish. J Heredity. 2005;96:185-96. doi:10.1093/jhered/ esi028.

Jensen MS, Finley FN. Teaching evolution using historical arguments in a conceptual change strategy. Sci Educ. 1995;79:147-66. doi: $10.1002 /$ sce. 3730790203 .

Jensen MS, Finley FN. Changes in students' understanding of evolution resulting from different curricular and instructional strategies. J Res Sci Teach. 1996;33:879-900. doi:10.1002/(SICI) 1098-2736(199610)33:8<879::AID-TEA4>3.0.CO;2-T.

Jiménez-Aleixandre MP. Thinking about theories or thinking with theories?: a classroom study with natural selection. Int J Sci Educ. 1992;14:51-61. doi:10.1080/0950069920140106.

Jiménez-Aleixandre MP, Fernández-Pérez J. Selection or adjustment? Explanations of university biology students for natural selection problems. In: Novak, JD. Proceedings of the Second International Seminar on Misconceptions and Educational Strategies in Science and Mathematics, vol II. Ithaca: Department of Education, Cornell University; 1987;224-32.

Jørgensen C, Enberg K, Dunlop ES, Arlinghaus R, Boukal DS, Brander $\mathrm{K}$, et al. Managing evolving fish stocks. Science. 2007;318:1247-8. doi:10.1126/science.1148089.

Jungwirth E. The problem of teleology in biology as a problem of biology-teacher education. J Biol Educ. 1975a;9:243-6.

Jungwirth E. Preconceived adaptation and inverted evolution. Aust Sci Teachers J. 1975b;21:95-100.

Jungwirth E. Should natural phenomena be described teleologically or anthropomorphically? - a science educator's view. J Biol Educ. 1977;11:191-6.

Kampourakis K, Zogza V. Students' preconceptions about evolution: how accurate is the characterization as "Lamarckian" when considering the history of evolutionary thought? Sci Edu 2007; 16:393-422.

Kampourakis K, Zogza V. Students' intuitive explanations of the causes of homologies and adaptations. Sci Educ. 2008;17:27-47. doi:10.1007/s11191-007-9075-9.

Kampourakis K, Zogza V. Preliminary evolutionary explanations: a basic framework for conceptual change and explanatory coherence in evolution. Sci Educ. 2009; in press.
Kardong KV. An introduction to biological evolution. 2nd ed. Boston: McGraw Hill; 2008.

Kargbo DB, Hobbs ED, Erickson GL. Children's beliefs about inherited characteristics. J Biol Educ. 1980;14:137-46.

Kelemen D. Why are rocks pointy? Children's preference for teleological explanations of the natural world. Dev Psychol. 1999a;35:1440-52. doi:10.1037/0012-1649.35.6.1440.

Kelemen D. Function, goals and intention: children's teleological reasoning about objects. Trends Cogn Sci. 1999b;3:461-8. doi:10.1016/S1364-6613(99)01402-3.

Kelemen D, Rosset E. The human function compunction: teleological explanation in adults. Cognition. 2009;111:138-43. doi:10.1016/ j.cognition.2009.01.001.

Keown D. Teaching evolution: improved approaches for unprepared students. Am Biol Teach. 1988;50:407-10.

Lawson AE, Thompson LD. Formal reasoning ability and misconceptions concerning genetics and natural selection. J Res Sci Teach. 1988;25:733-46. doi:10.1002/tea.3660250904.

MacFadden BJ, Dunckel BA, Ellis S, Dierking LD, Abraham-Silver L, Kisiel J, et al. Natural history museum visitors' understanding of evolution. BioScience. 2007;57:875-82.

Mayr E. The growth of biological thought. Cambridge: Harvard University Press; 1982.

Mayr E. What evolution Is. New York: Basic Books; 2001.

McCloskey M, Caramazza A, Green B. Curvilinear motion in the absence of external forces: naïve beliefs about the motion of objects. Science. 1980;210:1139-41. doi:10.1126/science.210. 4474.1139.

Moore R, Mitchell G, Bally R, Inglis M, Day J, Jacobs D. Undergraduates' understanding of evolution: ascriptions of agency as a problem for student learning. J Biol Educ. 2002;36:65-71.

Nehm RH, Reilly L. Biology majors' knowledge and misconceptions of natural selection. BioScience. 2007;57:263-72. doi:10.1641/ B570311.

Nehm RH, Schonfeld IS. Does increasing biology teacher knowledge of evolution and the nature of science lead to greater preference for the teaching of evolution in schools? J Sci Teach Educ. 2007;18:699-723. doi:10.1007/s10972-007-9062-7.

Nehm RH, Poole TM, Lyford ME, Hoskins SG, Carruth L, Ewers BE, et al. Does the segregation of evolution in biology textbooks and introductory courses reinforce students' faulty mental models of biology and evolution? Evo Edu Outreach. 2009;2: In press.

Nelson CE. Teaching evolution effectively: a central dilemma and alternative strategies. McGill J Educ. 2007;42:265-83.

Nelson CE. Teaching evolution (and all of biology) more effectively: strategies for engagement, critical reasoning, and confronting misconceptions. Integr Comp Biol. 2008;48:213-25. doi:10. 1093/icb/icn027.

Packard AS. Lamarck, the founder of evolution: his life and work with translations of his writings on organic evolution. New York: Longmans, Green, and Co; 1901.

Palumbi SR. Humans as the world's greatest evolutionary force. Science. 2001;293:1786-90. doi:10.1126/science.293.5536.1786.

Passmore C, Stewart J. A modeling approach to teaching evolutionary biology in high schools. J Res Sci Teach. 2002;39:185-204. doi:10.1002/tea.10020.

Pedersen S, Halldén O. Intuitive ideas and scientific explanations as parts of students' developing understanding of biology: the case of evolution. Eur J Psychol Educ. 1992;9:127-37.

Pennock RT. Learning evolution and the nature of science using evolutionary computing and artificial life. McGill J Educ. 2007;42:211-24.

Prinou L, Halkia L, Skordoulis C. What conceptions do Greek school students form about biological evolution. Evo Edu Outreach. 2008;1:312-7. doi:10.1007/s12052-008-0051-x.

Ridley M. Evolution. 3rd ed. Malden: Blackwell; 2004. 
Robbins JR, Roy P. The natural selection: identifying \& correcting non-science student preconceptions through an inquiry-based, critical approach to evolution. Am Biol Teach. 2007;69:460-6. doi:10.1662/0002-7685(2007)69[460:TNSICN]2.0.CO;2.

Rose MR, Mueller LD. Evolution and ecology of the organism. Upper Saddle River: Prentice Hall; 2006.

Rutledge ML, Mitchell MA. High school biology teachers' knowledge structure, acceptance \& teaching of evolution. Am Biol Teach. 2002;64:21-7. doi:10.1662/0002-7685(2002)064[0021: HSBTKS]2.0.CO;2.

Scharmann LC. Enhancing an understanding of the premises of evolutionary theory: the influence of a diversified instructional strategy. Sch Sci Math. 1990;90:91-100.

Settlage J. Conceptions of natural selection: a snapshot of the sensemaking process. J Res Sci Teach. 1994;31:449-57.

Shtulman A. Qualitative differences between naïve and scientific theories of evolution. Cognit Psychol. 2006;52:170-94. doi:10.1016/j. cogpsych.2005.10.001.

Sinatra GM, Southerland SA, McConaughy F, Demastes JW. Intentions and beliefs in students' understanding and acceptance of biological evolution. J Res Sci Teach. 2003;40:510-28. doi:10.1002/tea.10087.

Sinatra GM, Brem SK, Evans EM. Changing minds? Implications of conceptual change for teaching and learning about biological evolution. Evo Edu Outreach. 2008;1:189-95. doi:10.1007/ s12052-008-0037-8.

Southerland SA, Abrams E, Cummins CL, Anzelmo J. Understanding students' explanations of biological phenomena: conceptual frameworks or p-prims? Sci Educ. 2001;85:328-48. doi:10.1002/sce.1013.

Spiegel AN, Evans EM, Gram W, Diamond J. Museum visitors' understanding of evolution. Museums Soc Issues. 2006;1:69-86.

Spindler LH, Doherty JH. Assessment of the teaching of evolution by natural selection through a hands-on simulation. Teach Issues Experiments Ecol. 2009;6:1-20.
Stauffer RC (editor). Charles Darwin's natural selection: being the second part of his big species book written from 1856 to 1858 . Cambridge, UK: Cambridge University Press; 1975.

Stearns SC, Hoekstra RF. Evolution: an introduction. 2nd ed. Oxford, UK: Oxford University Press; 2005.

Strevens M. The essentialist aspect of naive theories. Cognition. 2000;74:149-75. doi:10.1016/S0010-0277(99)00071-2.

Sundberg MD. Strategies to help students change naive alternative conceptions about evolution and natural selection. Rep Natl Cent Sci Educ. 2003;23:1-8.

Sundberg MD, Dini ML. Science majors vs nonmajors: is there a difference? J Coll Sci Teach. 1993;22:299-304.

Tamir P, Zohar A. Anthropomorphism and teleology in reasoning about biological phenomena. Sci Educ. 1991;75:57-67. doi:10.1002/ sce.3730750106.

Tidon R, Lewontin RC. Teaching evolutionary biology. Genet Mol Biol. 2004;27:124-31. doi:10.1590/S1415-475720054000 100021.

Vlaardingerbroek B, Roederer CJ. Evolution education in Papua New Guinea: trainee teachers' views. Educ Stud. 1997;23:363-75. doi:10.1080/0305569970230303.

Wilson DS. Evolution for everyone: how to increase acceptance of, interest in, and knowledge about evolution. PLoS Biol. 2005;3: e364. doi:10.1371/journal.pbio.0030364.

Wood-Robinson C. Young people's ideas about inheritance and evolution. Stud Sci Educ. 1994;24:29-47. doi:10.1080/ 03057269408560038.

Zirkle C. The early history of the idea of the inheritance of acquired characters and of pangenesis. Trans Am Philos Soc. 1946;35:91151. doi: $10.2307 / 1005592$.

Zohar A, Ginossar S. Lifting the taboo regarding teleology and anthropomorphism in biology education-heretical suggestions. Sci Educ. 1998;82:679-97. doi:10.1002/(SICI)1098-237X (199811)82:6<679::AID-SCE3>3.0.CO;2-E. 